\title{
Anatomía caulinar y foliar de tres especies de plantas acuáticas
}

\author{
Alí V. Rubio, Giselle A. Valerio ${ }^{1}$ \\ Lilian Ferrufino ${ }^{2}$
}

\section{RESUMEN}

El aerénquima es un tejido de conducción que facilita el transporte de gases como el oxígeno. Estructuralmente es un tejido muy eficiente, ya que permite la flotación de determinados órganos y mantiene la firmeza de la planta con una cantidad mínima de células.

La mayoría de plantas acuáticas forman aerénquima constitutivo en sus raíces, tallos, pecíolos y hojas; pero en general se forma en respuesta a la hipoxia. Por lo tanto, los límites de adaptación entre estos tipos de plantas, basados en la presencia de aerénquima, pueden variar de acuerdo a las especies; siendo visibles en algunos órganos y no presentes en otros.

El objetivo principal del presente trabajo es la identificación de aerénquima en las especies: Salvinia auriculata, Eichhornia crassipes, en el jardín botánico, y Nymphaea caerulea en la laguna de la Universidad Nacional Autónoma de Honduras. Para lograrlo se colectaron muestras de pecíolo, pedúnculo y hoja de las tres especies.

En Nymphaea caerulea se encontró aerénquima de tipo lisígeno, con inclusiones celulares en forma de esclereidas. En el caso de Eichhornia crassipes se observó un aerénquima esquizógeno, con presencia de estiloides. Sin embargo, en Salvinia auriculata se observa un reducido aerénquima esquizógeno y la ausencia de inclusiones celulares.

Palabras clave: aerénquima, lisígeno, esquizógeno, inclusiones, acuáticas.

1 Estudiantes, Carrera de Biología, Departamento de Biología, Facultad de Ciencias, UNAH: clasesbioar@hotmail.com, valerioadri90@yahoo.es

2 Profesor universitario y asesor, Departamento de Biología, Facultad de Ciencias, UNAH: ferrufinolilian@yahoo.com 


\section{ABSTRACT}

The aerenchyma is a tissue of conduction that facilitates the transportation of gases, for example oxygen. in its structure it is very efficient and produces buoyancy in many organs be keeping firmness in plants with a reduced number of cells. Most aquatic plants develop constitutive aerenchyma in their roots, stems, petioles and leaves. In general aerenchyma occurs in response to hypoxia. Therefore, the limits of adaptation in these plants, based on the presence of aerenchyma, may vary according to the type of specie. It may be present in some organs and not present in others.

The main purpose of this research was the identification of aerenchyma in: Salvinia auriculata, Eichhornia crassipes from the Botanical Garden and Nymphaea caerulea from the Universidad Autónoma de Honduras lagoon. Petiole, peduncle and leaves samples were taken of the three species. Lysigenous aerenchyma and cell inclusions as sclereids were found in Nymphaea caerulea; schizogeny aerenchyma with styloids inclusions were found in Eichhornia crassipes. However, in Salvinia auriculata reduced schizogeny aerenchyma can be observed without cell inclusions.

Key words: aerenchyma, lysigenous, schizogeny, cell inclusions, aquatic plants. 


\section{INTRODUCCIÓN}

Los antecesores de las plantas superiores fueron formas acuáticas que para iniciar la colonización de hábitats secos y nutricionalmente pobres, debieron sufrir profundas transformaciones en su proceso evolutivo. Tal acontecimiento ocurrió entre los períodos silúrico y devónico, hace aproximadamente 400 millones de años, época que culminó con la aparición de las plantas superiores (cormófitos) adaptadas al ambiente terrestre-aéreo (Judd et al. 2002).

Posteriormente, algunas de estas plantas terrestres retornaron al ambiente acuático primitivo, configurando actualmente menos del $1 \%$ del total de especies de plantas vasculares (Ramírez, 1978), aunque por su alto grado de especialización constituyen un grupo biológicamente importante.

Para el estudio de aspectos relacionados con la anatomía y fisiología de los vegetales superiores, se prestan muy bien las plantas acuáticas, debido a su particular estructura, a su abundancia y a las facilidades de su recolección y cultivo (Hauenstein y Troncoso, 1984). Las plantas acuáticas, generalmente, presentan abundante tejido aerífero (aerénquima) formado por células que dejan toda una red de grandes espacios intercelulares.

Por estos espacios circulan gases provenientes del agua circundante o de los procesos de fotosíntesis y respiración. Estos tejidos favorecen la flotación de las plantas y permiten el transporte de oxígeno a los órganos sumergidos. Las plantas que viven totalmente sumergidas están bajo condiciones en donde el paso de la luz es restringido, por lo que poseen un extenso sistema intercelular con espacios en los cuales la difusión de gases ocurre fácilmente (Fahn, 1982).

Puede tener un origen cortical o epidérmico, siendo tejido de felema (súber) que se deriva del felógeno. Las células se dividen en capas elongadas axialmente, en intervalos constantes y las células que quedan en el medio se mantienen pequeñas. En este patrón de alargamiento se va empujando la capa anterior de células hacia afuera, lo que va formando cámaras de aire. Las células alargadas forman las capas radiales y las no alargadas forman las paredes tangenciales (Fahn, 1982). Se ha apuntado que en ciertas plantas cuando el suministro de oxígeno es bajo, se dispara una estimulación anaeróbica en la que se produce metileno, lo que causa un incremento en la actividad de la celulosa. 
La actividad de la celulosa provoca desintegración de las paredes celulares dando como resultado el aerénquima. Lo que a su vez sugiere que hay una competencia por agua entre las células, luego de que las paredes han sido debilitadas por la celulosa. Las células más fuertes sobreviven y se alargan, mientras que las células débiles pierden agua hasta que mueren (Kawase y otros, 1980).

Plantas mesófitas, usualmente herbáceas, que viven en lugares húmedos y epífitas, con frecuencia desarrollan aerénquima. Se pueden citar ejemplos como: Musaceae (Musa, Ensete) Heliconiaceae (Heliconia), Zingiberaceae (Alpinia, Renealmia), Marantaceae (Maranta, Calathea), Bromeliaceae (Aechmea, Vriesia) y Poaceae (Bouteloua). Algunas gramíneas mesófitas cultivadas, también desarrollan aerénquima, tales como la cebada (Hordeum vulgare), el trigo (Triticum vulgare), el maíz (Zea mayz), el arroz (Oryza sativa); también otros cultivos como el tomate (Lycopersicon esculentum), el girasol (Helianthus annuus) y el sauce (Salix fragilis) (Flores, 1994).

Como una estrategia alternativa, el aerénquima comprime una alta proporción de gases en espacios lagunares para proveer oxígeno a la planta. Forma un sistema de aireación compuesto por lagunas interconectadas desde la parte baja del tallo hasta las hojas. Los espacios dentro de los órganos pueden ser esquizógenos o lisígenos (Drew y otros, 2000; Kawase y otros, 1980). En algunas plantas es posible encontrar ambos tipos, tales como en Sagittaria lancifolia (Drew y otros, 2000). El aerénquima no solo provee un sistema interno de oxígeno, sino que a la vez reduce el número de células que consumen oxígeno. Por lo tanto, la formación de aerénquima está estrechamente relacionado con la tolerancia a los suelos húmedos y hábitats acuáticos (Drew y otros, 2000).

Nymphaea caerulea es una especie de angiospermas de la familia Nymphaceae. Las hojas son enteras o ligeramente onduladas, orbicular u orbicular-ovada, casi peltada de 30-40 cm de diámetro, con la superficie adaxial verde, superficie abaxial verde con pequeños puntos púrpura y con los márgenes de color morado. Las flores tienen entre $7-15 \mathrm{~cm}$. de un extremo a otro. Los sépalos tienen líneas y puntos negros, muy marcados. Presenta de 14-20 pétalos, lanceolados, ligeramente azul por la parte superior y blanco opaco en la parte inferior. Posee de 50-73 estambres, con filamentos largos ( 0.5 en los filamentos externos), esbeltos y de azul pálido (Conard, 1905).

Eichhornia crassipes pertenece a la familia Pontederiaceae y es una hierba flotante que se enraíza en el barro, generalmente está en densas esteras con plántulas 
adjuntas en estolones verdes, las raíces van del negro-azulado al púrpura, pubescente, engrosadas en la parte superior y con los ápices largos y oscuros. Las hojas forman rosetas, láminas foliares redondeadas o elípticas, de color verde brillante, de $15 \mathrm{~cm}$ de ancho. Los pecíolos pueden tener $30 \mathrm{~cm}$ o más, especialmente bulbosos cerca de la base. La inflorescencia es una espiga de $30 \mathrm{~cm}$ de largo, aproximadamente. Las flores son azul-lavanda con manchas amarillo, de $2 \mathrm{~cm}$ de ancho, labiadas, con 6 pétalos y 6 estambres. El fruto es una cápsula con muchas semillas (Florida Exotic Pest Plant Council).

Salvinia auriculata es una especie de helecho acuático perenne de la familia Salviniaceae. Posee rizomas rastreros, pilosos, en cada nudo con 2 frondes flotantes. Las hojas flotantes aparentemente son opuestas, con o sin quilla; abarquilladas, a veces planas; haz con pelos ubicados de a 4 sobre papilas o sin ellas, cubriendo toda la superficie de la lámina o limitados al margen de la misma; envés piloso. Presentan un órgano sumergido con o sin eje primario aparente, simple o ramificado, con lacinias, lleva uno a varios ejes fértiles, también simples o ramificados, con numerosos soros íntegramente cerrados, sésiles o pedicelados (Guía de Consulta Diversidad Vegetal).

Los objetivos de esta investigación son identificar y describir el aerénquima de Nymphaea caerulea (Nymphaceae), Eichhornia crassipes (Pontederiaceae) y Salvinia auriculata (Salviniaceae) que habitan en el jardín botánico y la laguna de la Universidad Nacional Autónoma de Honduras.

\section{MATERIALES Y MÉTODOS}

\section{Área de estudio}

El jardín botánico y la laguna de la Universidad Nacional Autónoma de Honduras se encuentran en las siguientes coordenadas: $14^{\circ} 5^{\prime} 7^{\prime \prime} \mathrm{N}, 87^{\circ} 9^{\prime}$ 47" W. El jardín botánico está localizado al norte del edificio de Ciencias Biológicas de la UNAH y está adscrito a la Escuela de Biología en Tegucigalpa. Esta área de aproximadamente tres manzanas de terreno, con secciones casi planas y pendientes, cuenta con un área de plantas acuáticas, distribuidas en tres estanques artificiales (ver cuadro 1, figura 1). La laguna se encuentra camino al Observatorio Astronómico, en la calle secundaria de acceso a la UNAH (ver figura 2). 
Las plantas utilizadas para la identificación y descripción de aerénquima en esta investigación fueron: Nymphaea caerulea, de la que se tomaron muestras de pecíolo, pedúnculo y hoja; la Eichhornia crassipes, de la que se tomaron muestras de hoja, tallo y pecíolo; y la Salvinia auriculata, de la que se tomaron muestra de hoja.

Todas las muestras fueron fijadas en formol-ácido acético-alcohol (FAA). Se hicieron cortes transversales; en la hoja de Nymphaea caerulea se hizo un corte radial. Los cortes fueron hechos a mano alzada con hojas de afeitar y montadas en porta y cubreobjetos con una solución de glicerol. Se tomaron microfotografías de cada corte en las que se puede observar el aerénquima.

Cuadro 1. Sitios de colecta del material para la identificación y la descripción de aerénquima

\begin{tabular}{|c|c|c|}
\hline \multirow[t]{2}{*}{ Especies } & \multicolumn{2}{|c|}{ Lugar de colecta } \\
\hline & Jardín botánico & Laguna \\
\hline Nymphaea caerulea & & $\mathscr{J}$ \\
\hline Eichhornia crassipes & $\mathcal{J}$ & \\
\hline Salvinia auriculata & $\mathcal{J}$ & \\
\hline
\end{tabular}

Figura 1. Mapa del área que ocupa el jardín botánico

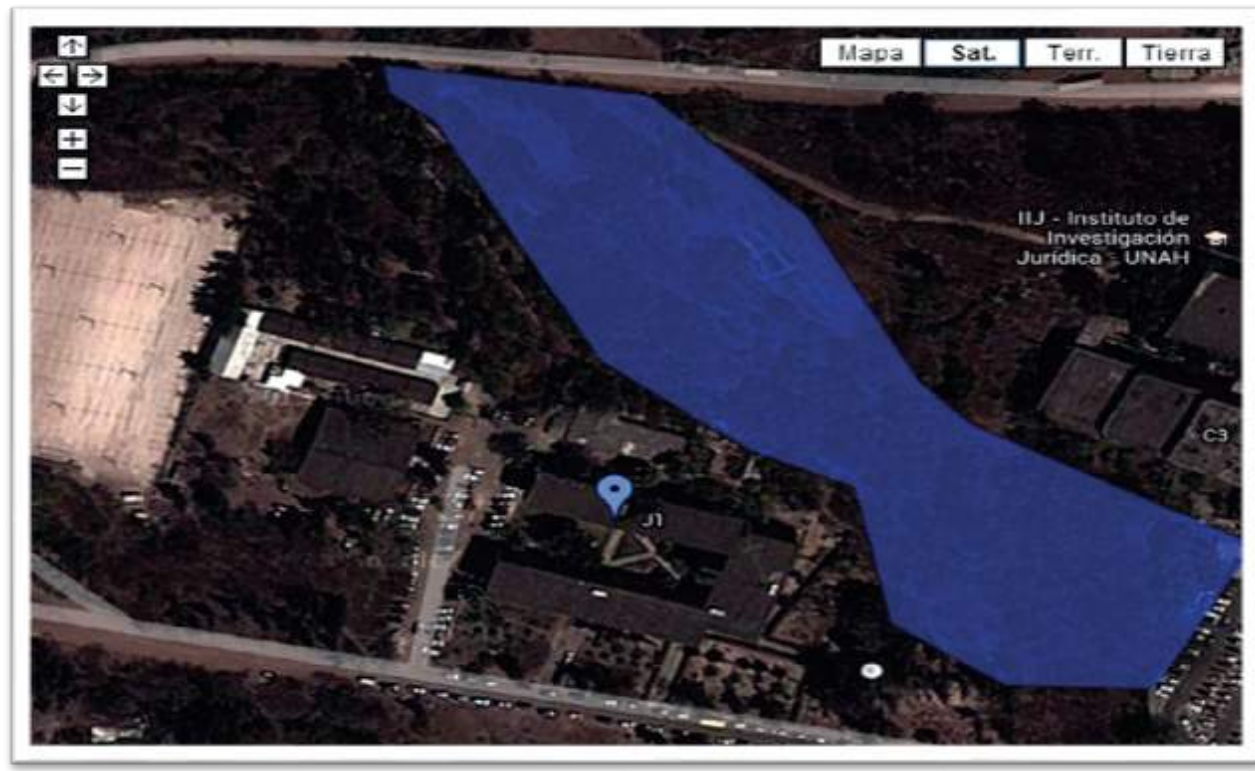


Figura 2. Laguna en la segunda calle de acceso a la UNAH

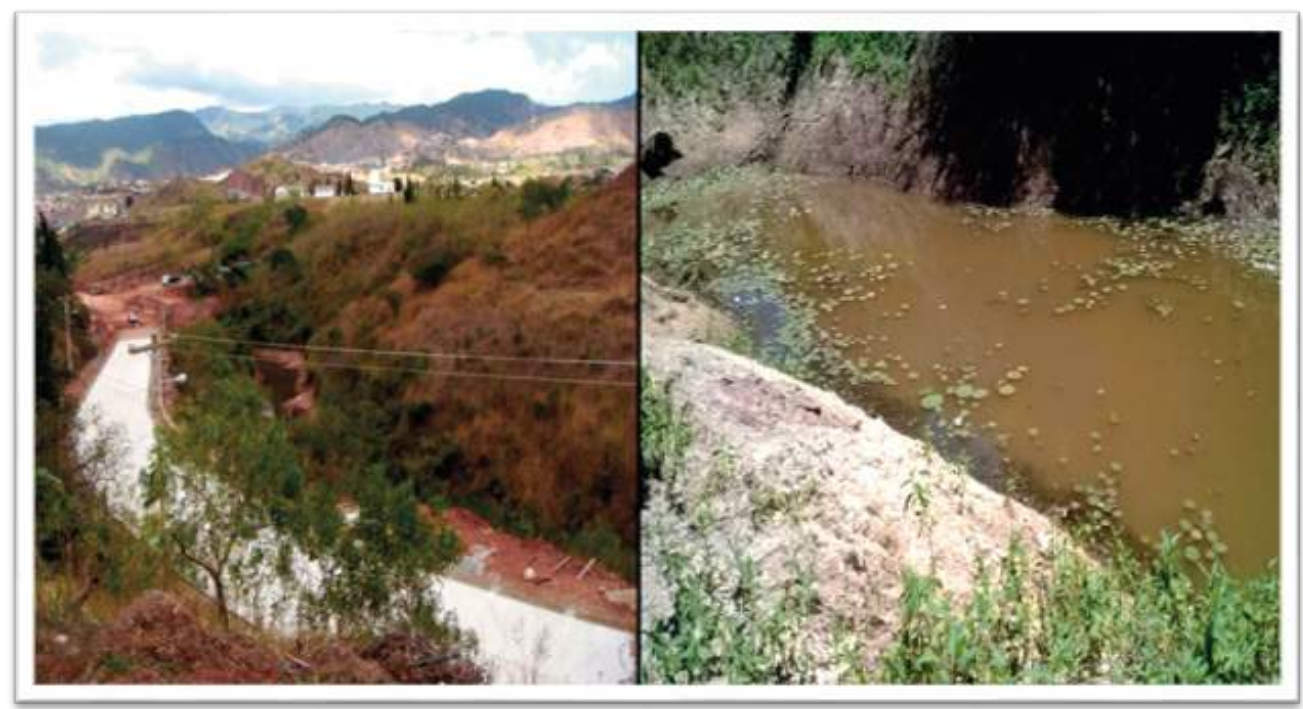

\section{RESULTADOS}

\section{Anatomía caulinar}

Se encontraron espacios aeríferos delimitados por septos, situados en la corteza como las partes del aerénquima, esto en el pecíolo y pedúnculo floral de Nymphaea caerulea; tallo y pecíolo de Eichhornia crassipes; el aerénquima es esquizógeno en Eichhornia crassipes y lisígeno en Nymphaea caerulea. En ambas especies, los haces vasculares están rodeados por los espacios aeríferos.

En tallo y peciolo de Eichhornia crassipes se observaron estiloides, sin embargo, en los espacios aeríferos de $\mathrm{N}$. caerulea las inclusiones celulares están ausentes en el pedúnculo; para el pecíolo se encontraron astroesclereidas siguiendo un patrón que se establece alrededor de los espacios aeríferos. Los haces vasculares en el tallo de Eichhornia crassipes están dispersos (atactostela), lo que confirma que es una monocotiledónea. En Nymphaea caerulea en el pecíolo y pedúnculo floral se identificó un haz vascular central y haces vasculares formando una eustela en la corteza. 


\section{Anatomía foliar}

En la hoja de Nymphaea caerulea y Eichhornia crassipes se observó aerénquima en el mesófilo para ambas especies. En N. caerulea y E. crassipes la hoja presenta un haz vascular central en corte transversal tangencial y en el corte transversal radial se pueden observar haces vasculares continuos y separados a cierta distancia siguiendo un patrón de fila. En la primera especie se observaron astroescleriedas y esclereidas columnares que se encuentran en los extremos ramificados que se proyectan hacia los espacios intercelulares del parénquima lagunoso; mientras que en la segunda especie se presentan estiloides. En Eichhornia crassipes hay presencia de estiloides dispersos en el mesófilo. Los estiloides son llamados cristales prismáticos o "pseudorafidios", generalmente son más gruesos que los rafidios y se encuentran de una forma solitaria (Prychid y Rudall, 1999). En Salvinia auriculata se identificó aerénquima en la cara adaxial de la hoja y una pequeña capa con espacios ordenados en hilera, separados por septos de una fila de células esquizógenas (ver figuras 3, 4, 5, 6 y 7 ).

\section{DISCUSIÓN Y CONCLUSIONES}

En este estudio se observó la presencia del aerénquima para Nymphaea caerulea, Eichhornia carissipes y Salvinia auriculata, en esta última muy reducido. El aerénquima se ha desarrollado en diferentes grupos de plantas desde pteridofitas hasta angiospermas. Dal y colaboradores (2002) comentan que esto sería el resultado de una evolución paralela, debido a las condiciones ambientales en donde se desarrollan estas especies acuáticas.

El aerénquima lisígeno se puede encontrar en la familia Nymphaeacea y taxones relacionados (Jung y otros, 2008). Para N. caerulea se confirma la presencia de aerénquima lisígeno; sin embargo, en E.crassipes posee un aerénquima esquizógeno, así como en $S$. auriculata. El aerénquima es una estructura que se forma como una respuesta inteligente para hacer de suelos muy húmedos o inundados un lugar accesible a formas de vida como las plantas. Es una adaptación que puede ser facultativa para plantas terrestres que en suelos húmedos lo desarrollan y es constitutivo para plantas acuáticas en las cuales sus células se codifican por sí mismas. 
Las astroesclereidas son células muertas con paredes celulares gruesas, lignificadas, que tienen como función proporcionar soporte. Martínez y Gómez-Sánchez (2006) encuentran astroesclereidas en el género Nymphoides de la familia Menyanthaceae, una planta acuática que habita en México. En este estudio en N. caerulea se observó en la hoja astroesclereidas y esclereidas columnares. Dal y González (2002) reportan la presencia de astroesclereidas en el mesofilo de Nymphoides indica, Nymphaea amazonum y Victoria cruziana, y esclereidas columnares en el parénquima de empalizada de Nymphaea.

Los cristales de oxalato de calcio son inclusiones celulares que están asociados con la formación de espacios aeríferos; algunas plantas acuáticas los poseen proyectándose hacia el interior de dicho espacios (Rudall, 2009). Mahmood y colaboradores (2005) comentan que la presencia de estos cristales de $E$. crassipes se debe a la acumulación de oxalato de calcio en la planta. Además, Lopes y colaboradores (2009) comentan que la exposición de $E$. crassipes a algunos contaminantes podría modificar la morfología y anatomía de las hojas, tales como el tamaño de las hojas en los espacios aeríferos.

Prychid y Rudall (1999) comentan que los estiloides son un carácter sinapomórfico, es decir, un carácter derivado compartido por un grupo de especies que se presenta en algunas familias de monocotiledóneas, entre ellas la familia Pontederiaceae que incluye a la especie Eichhornia crassipes. En este estudio se confirma la presencia de dichas inclusiones de tipo estiloides en $E$. crassipes.

La presencia de tejido de aerénquima de tipo lisígeno y esquizolisígeno, así como esclereidas y cristales en forma de estiloides, son características anatómicas que presentan estas especies estudiadas. No obstante, otras características podrían ser observadas en diferentes especies de plantas acuáticas. 
Fiqura 3. Hoia de Nvmphaea caerulea

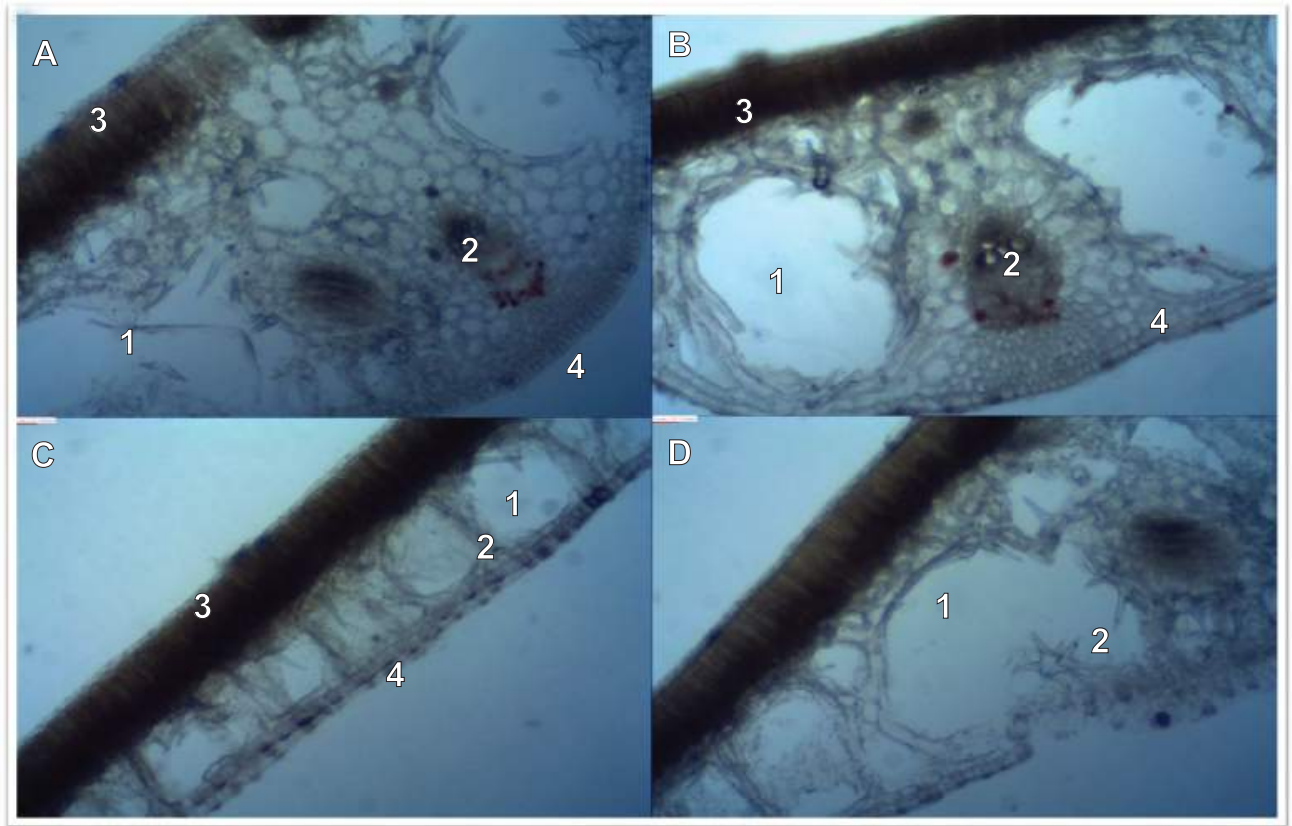

A. Corte transversal tangencial. B. Corte transversal radial: 1. Espacio aerifero, 2. Haz vascular, 3. Epidermis adaxial, 4. Epidermis abaxial. C. Mesófilo: 1. Espacio aerífero, 2. Septo, 3. Epidermis adaxial, 4. Epidermis abaxial. D. 1. Aerénquima, 2. Astroesclereidas.

Figura 4. Pecíolo Nymphaea caerulea

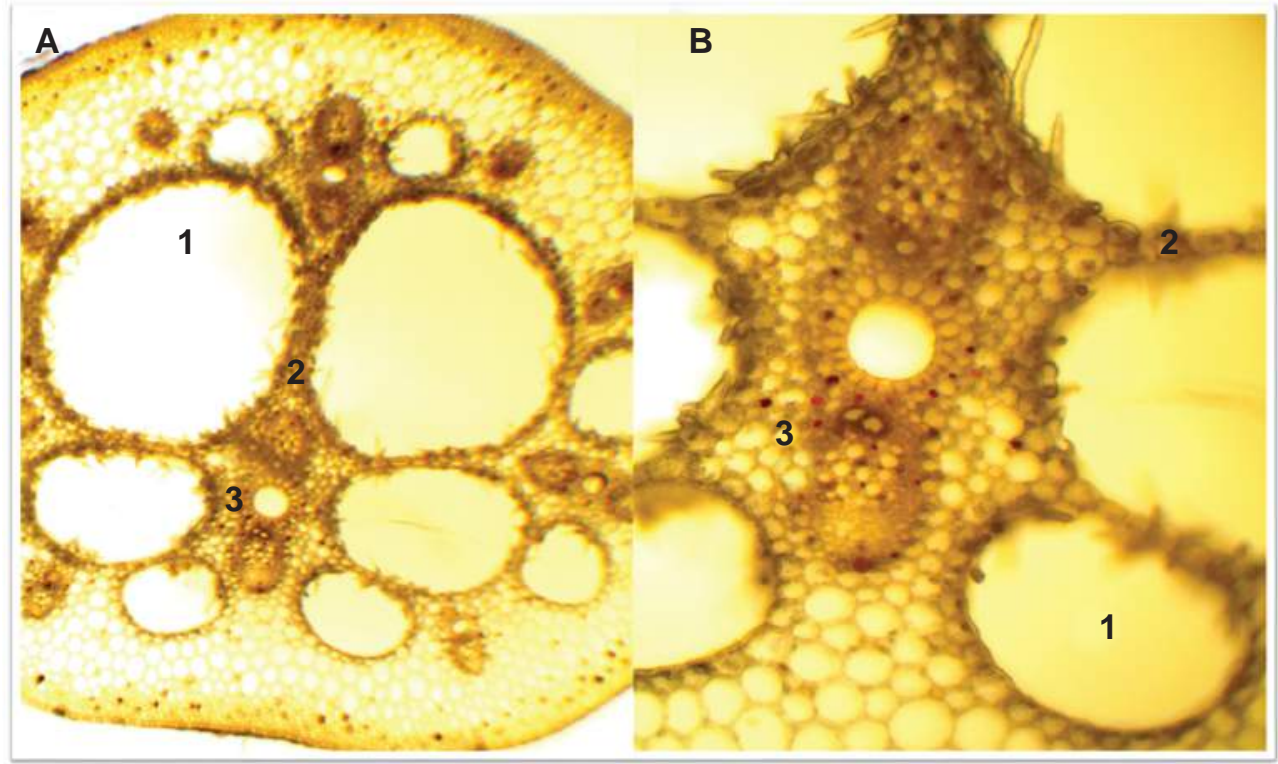

A y B: Pedúnculo floral, 1. Espacio aerífero, 2. Septo, 3. Haz vascular. 
Figura 5. Pedúnculo floral Nymphaea caerulea

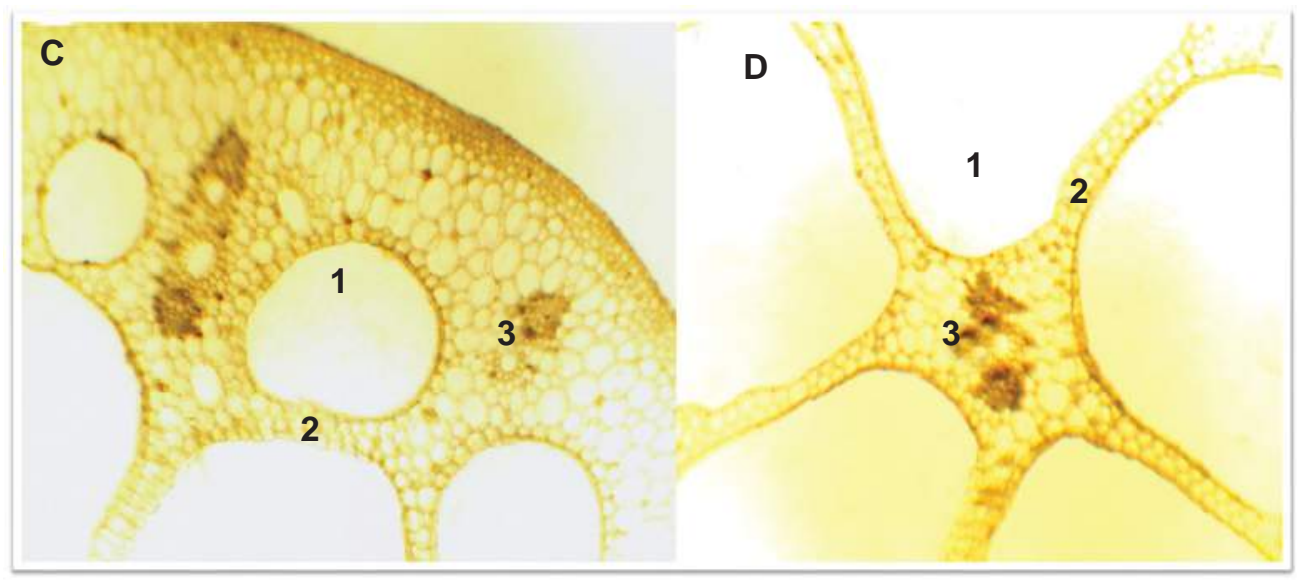

C y D: Pedúnculo floral, 1. Espacio aerífero, 2. Septo, 3. Haz vascular.

Figura 6. Pecíolo y tallo de Eichhornia crassipes

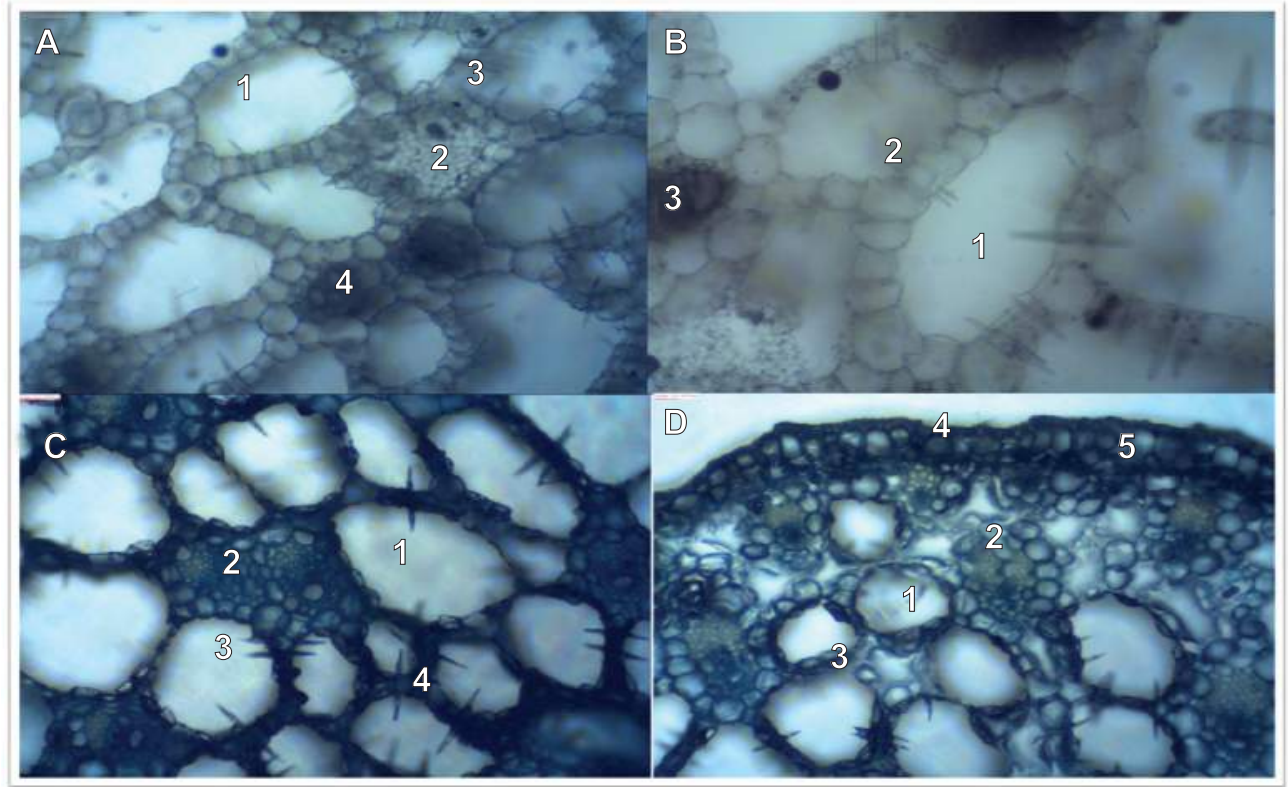

A. Pecíolo: 1. Espacio aerífero, 2. Parénquima, 3. Septo, 4. Haz vascular. B. Pecíolo (detalle): 1 y 2. Aerénquima con estiloides, 3. Haz vascular. C. Tallo (detalle): 1. Espacio aerífero, 2. Haz vascular, 3. Estiloides, 4. Septo. D. Tallo: 1-3. Aerénquima, 2. Haz vascular, 4. Epidermis, 5. Corteza. 
Fiqura 7. Corte transversal de hoia

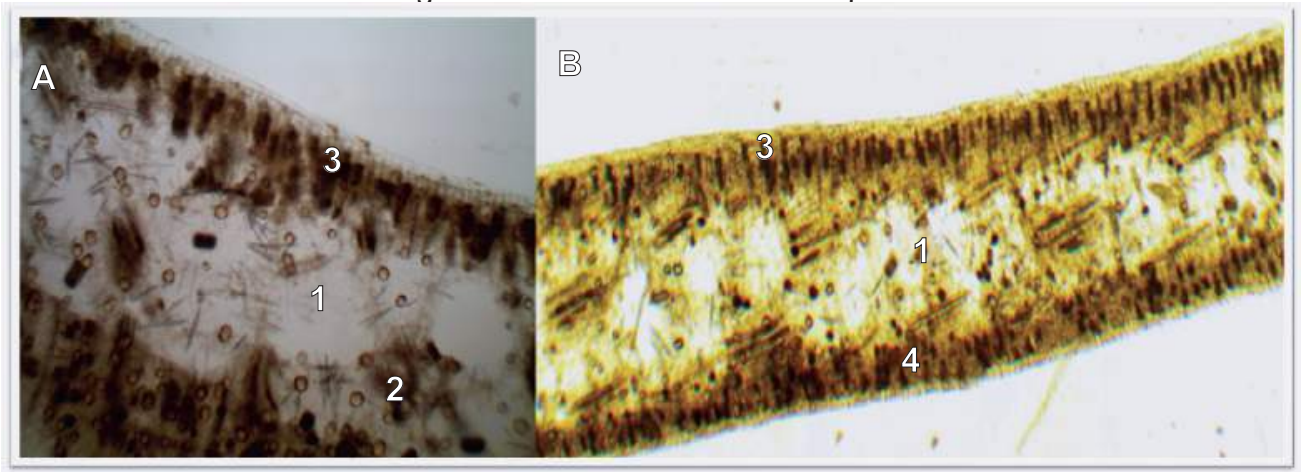

A y B. Eichhornia crassipes. 1. Aerénquima, 2. Haz vascular, 3. Epidermis adaxial, 4. Epidermis abaxial.

Figura 8. Detalle inclusiones celulares

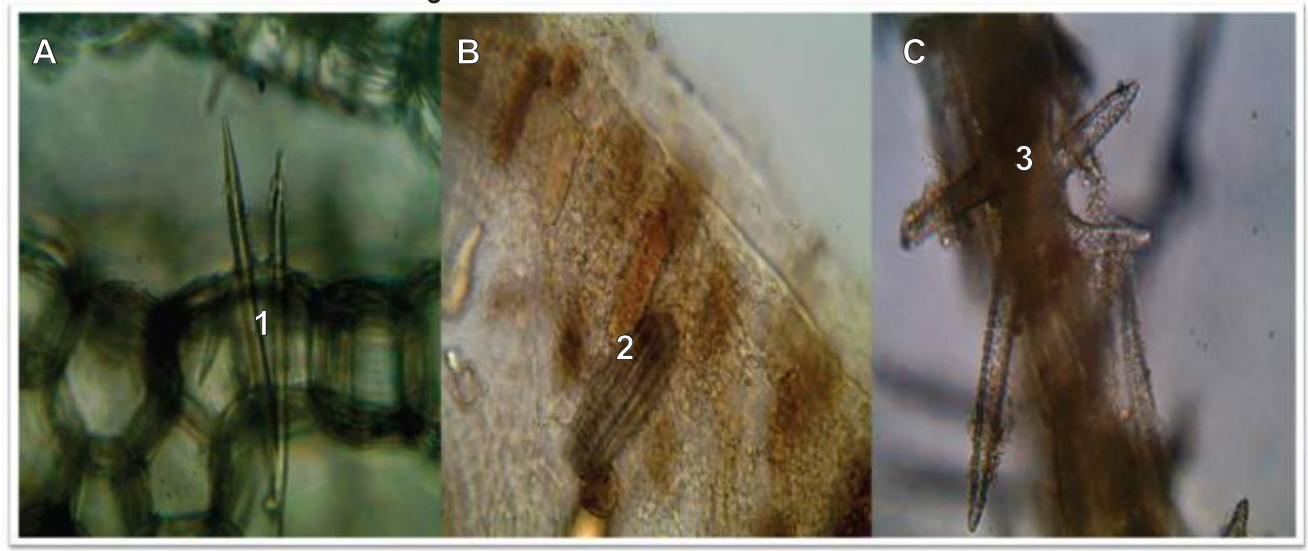

A y B. Eichhornia crassipes: 1. Estiloide, 2. Rafidio. C. Nymphaea caerulea, 3. Astroesclereida

Fiqura 9. Corte transversal de hoia Salvinia auriculata

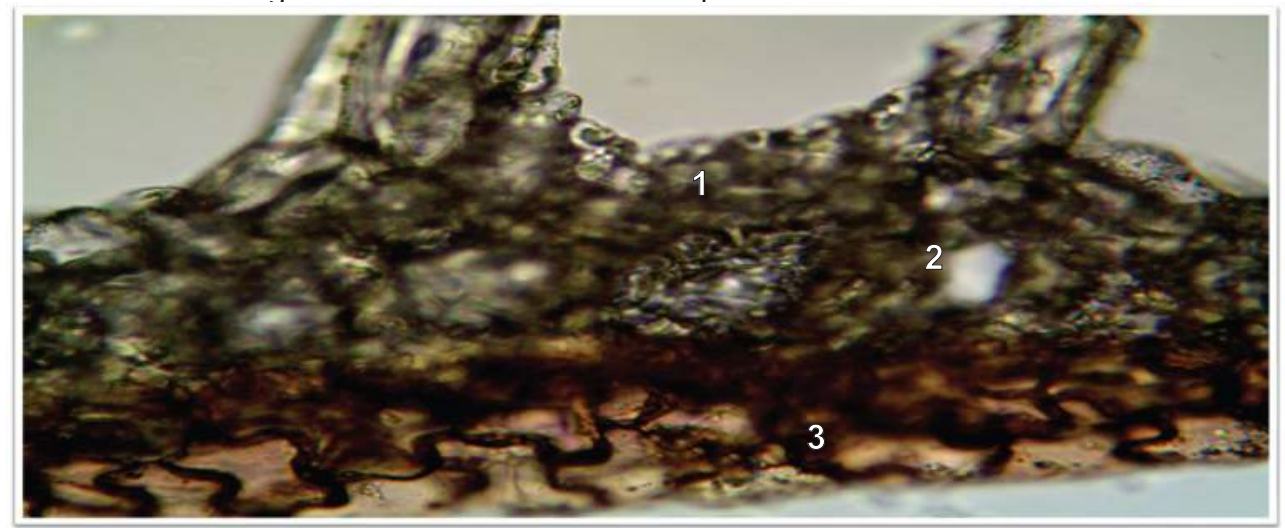

1. Epidermis adaxial, 2. Espacio aerífero, 3. Epidermis abaxial. 


\section{BIBLIOGRAFÍA}

Conard, S. Henry. (1905). The Waterlilies. A Monograph of The Genus Nymphaea. Baltimore: The Lord Baltimore Press, The Friedenwald Company.

Dal, M.P. y González, A. M. (2002). Anatomía foliar en Nyphoides indica, Nymphaea amazonum y Victoria cruziana, especies con lámina foliar flotante del macrosistema Iberá. Facultad de Ciencias Agrarias, UNNE. Argentina.

Drew, M. C.; He, C.J. y Morgan, P. W. (2000). Programmed cell death and aerenchyma formation in roots. Trends in Plants Science, 5(3), 123-127.

Fahn, A. (1982). Plant Anatomy. Oxford: Editorial Pergamo Press.

Flores- Vindas, E. (1994). La planta: estructura y función. Costa Rica: Editorial Tecnológica de Costa Rica.

Florida Exotic Pest Plant Council. Eichhornia crassipes (Mart.) Solms-Laub. Florida: Center for Invasive Species and Ecosystem Health at the University of Georgia. Recuperado de: http://www.fleppc.org

Guía de Consulta Diversidad Vegetal, FACENA (UNNE) PTERIDOFITAS-Salviniaceae. Argentina: Facultad de Ciencias Exactas y Naturales y Agrimensura (UNNE). Recuperado de: http://exa.unne.edu.ar

Hauenstein, E. y Troncoso, E. (1984). Utilización didáctica de macrófitos acuáticos en la enseñanza de la biología, aula (2000). 2, 50-73. Chile: Recuperado de: http://repositoriodigital.uct.cl

Judd, W. S., Campbell C. S., Kellogg E. A. \& Stevens P. F. 2002. Plants systematics. A phylogenetic approach. Mass., USA., Publisher Sunderland.

Jung, J.; Cho Lee, S.; Keun Choi, H. (2008). Anatomical Patterns of Aerenchyma in Aquatic and Wetland Plants. Journal of Plant Biology, 51(6), 428-439.

Kawase, M.; Whitmoyer, E. R.. (1980). Aerenchyma in Watterlogged Plants. Departamento de Horticultura y Laboratorio de Microscopio Electrónico, Centro de Desarrollo e Investigación de Agricultura de Ohio.

Lopes, A.; Da Rosa-Osman, S. M.; Fernández M., T. P. (2009). Effects of crude oil on survival, morphology and anatomy of two aquatic macrophytes from the Amazon floodplains. Hidrobiologia, 636: 295-305.

Mahmood, Q.; Zheng, P.; Siddiqi, M. R.; Islam, E.; Azim M. R. \& Hayat, Y. (2005). Anatomical studies on water hyacinth (Eichhornia crassipes (Mart.) Solms) under the influence of textile wastewater. J. Zhejiang Univ. SCl, 6B (10), 991-998.

Martínez, M. y Gómez-Sánchez, M. (2006). Descripción anatómica vegetativa de dos especies de Nymphoides (Menyanthaceae). Revista Mexicana de Biodiversidad, 77(1), 81-87. 
Prychid, C.J. \& P. J. Rudall. (1999). Calcium Oxalate Crystals in Monocotyledons: A Review of their Structure and Systematics. Annals of Botany, 84, 725-739.

Ramírez, C. (1978). Las plantas acuáticas vasculares y su ambientación en ambientes límnicos y salobres del sur de Chile. Archivos de Biología y Medicina Experimentales, 11(2), 48-49.

Rudall, P. (2009). Anatomía de las plantas con flores, introducción a la estructura y el desarrollo. Zaragoza: Editorial de la Universidad de Zaragoza. 